\title{
AN INTERESTING CASE OF NEPHROPATHIC CYSTINOSIS - LIGNAC FANONIS SYNDROME
}

Srinivas M. Ganagi ${ }^{1}$, Shivaraj Budihal ${ }^{2}$

\section{HOW TO CITE THIS ARTICLE:}

Srinivas M. Ganagi, Shivaraj Budihal. "An interesting case of Nephropathic Cystinosis - Lignac Fanonis Syndrome". Journal of Evolution of Medical and Dental Sciences 2014; Vol. 3, Issue 33, August 07;

Page: 8933-8937, DOI: 10.14260/jemds/2014/3147

ABSTRACT: Cystinosis is a rare autosomal recessive lysosomal storage disorder characterized by the intracellular accumulation of cystine crystal in various organs. Three forms have been described infantile, adolescent and adult. Cystinosis is diagnosed by the presence of typical cystine crystals in the cornea on slit-lamp examination or the 50 to 100 fold elevated levels of free, non-protein cystine within polymorphonuclear leucocytes or cultured fibroblasts. We report a $10 \mathrm{yr}$ old female who presented with infantile form of cystinosis.

KEYWORDS: Cystinosis, Fanconi syndrome, Corneal deposit.

CASE REPORT: A 10 yrs old female was brought to hospital by her mother to our hospital with complaints of haziness in both corneas since 5 months of age which was progressively increasing and that baby avoided looking at bright light since one year of age more so since past two years.

On ocular examination both eyes were orthophoric, anterior segment examination of both eyes showed hazy cornea (Fig. 1) with deposition of multiple crystals in entire thickness of corneal stroma more in periphery than at the centre (Fig. 2) Iris details were hazy with normal AC depth, pupillary reaction and clear lens in both eyes. Fundus examination of both eyes showed a mildly hazy media due to overlying corneal changes. Mild disc pallor was noted with normal retinal vasculature. Macular examination showed chorioretinal degeneration with absent foveal reflex (Fig 3, 4). Best corrected visual acuity in both eyes was 6/60.

General examination showed mental retardation with short stature (Fig 5), stunted growth, sparse hair and defective dentition (Fig 6). CVS and RS were normal and abdominal examination showed hepatomegaly.

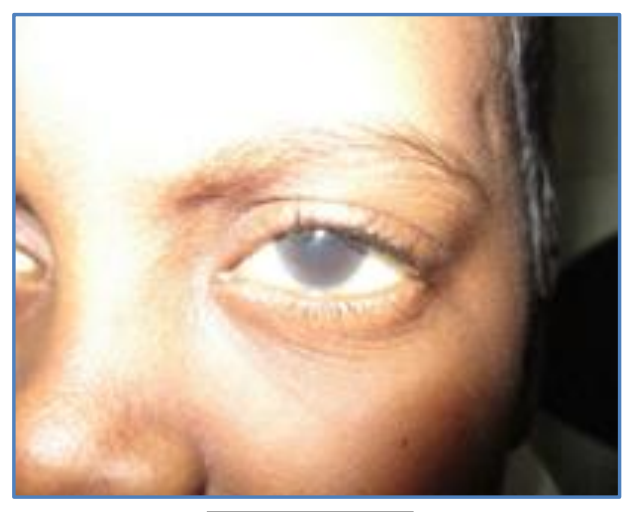

Fig. 1

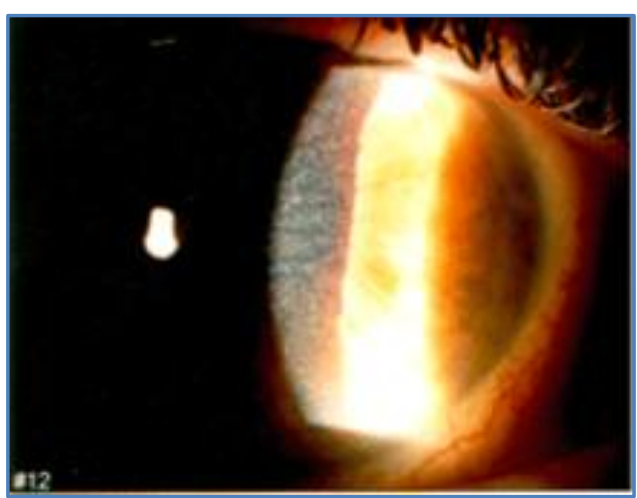

Fig. 2 


\section{CASE REPORT}

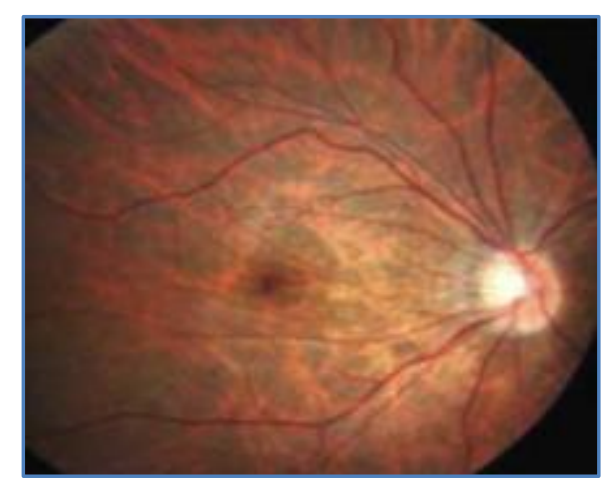

Fig. 3

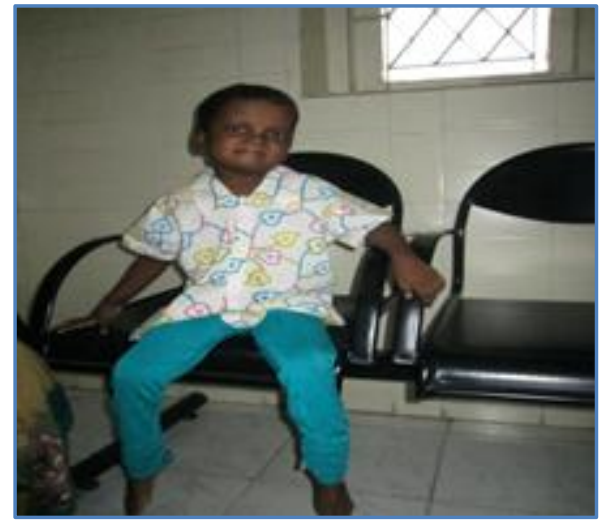

Fig. 5

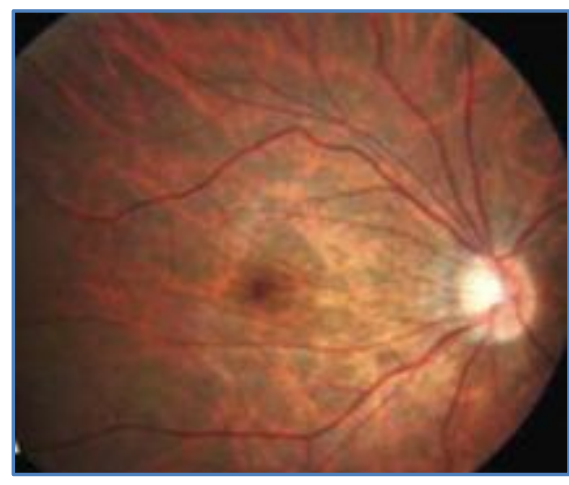

Fig. 4

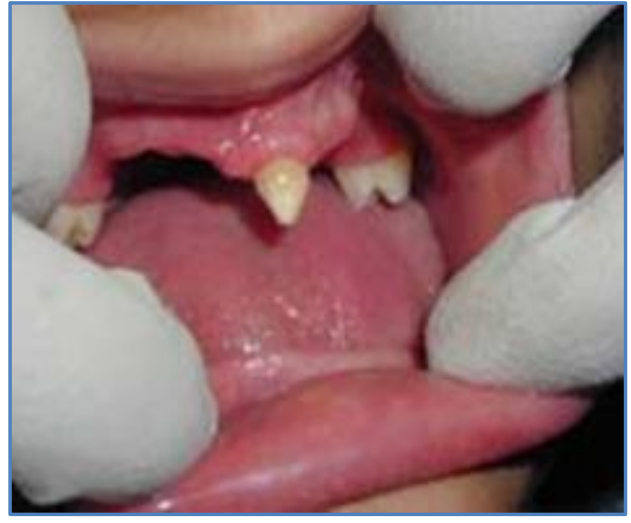

Fig. 6

BIRTH HISTORY: Third degree consanguineous marriage. Antenatal period of mother was uneventful. Fourth born female child, full term normal delivery. First male sibling died of hydrocephalus at age of four months. Second male sibling died of cardiac anomalies at age of eighteen months. Third male sibling died of gastrointestinal tract anomalies of seven months.

DEVELOPMENTAL HISTORY: Delayed motor and social milestones. Not able to stand or walk, even with support. Able to comprehend commands but unable to express herself.

SYSTEMIC HISTORY: Can take only semisolid food, vomits frequently. Passes copious volume of urine, no specific odour. Patient has had repeated attacks of UTI from age of 2yrs. Patient had pathological fracture of Supracondylar fracture of left femur at age of $4 \mathrm{yrs}$. 
TREATMENT HISTORY: At age of 6months patient was diagnosed as nephropathic cystinosis with generalized aminoaciduria and at age of 4yrs with associated Renal Rickets. On Urine Chromatography all amino acids were detected.

Patient is on treatment with oral cysteamine $50 \mathrm{mg} / \mathrm{kg}$ QID, Pottasium citrate, Calcitriol, Ferrous sulphate and multivitamins. Patient has been instructed to take plenty of oral fluids. Periodic assessment of renal parameters is being carried out by the nephrologist. Topical cysteamine $0.5 \%$ QID has been started and is being followed up with regular ocular examinations.

DISCUSSION: First described by Abderhalden ${ }^{1}$ in 1903 cystinosis is a rare autosomal recessive lysosomal storage disorder resulting from mutations in the gene CTNS mapped to chromosome no 17p. Mutation causes the defective transport of the amino acid cystine out of the lysosome ${ }^{2}$ leading to its intracellular accumulation in various organs. The incidence of nephropathic cystinosis is approximately 1 in 100,000-200,000 live births ${ }^{3}$ with highest prevalence in patients with French Canadian ancestry.

In 1941, Burki first reported the corneal crystal as an ocular manifestation associated with nephropathic cystinosis 4 . The histological findings of cystine crystals in the choroid was first published by Bickel et al in 1952.5 Francois described the clinical appearance of presumed tapetoretinal degeneration in 1964.6

Three types of cystinosis have been described, including infantile (nephropathic), adolescent, and adult (non-nephropathic) type. Most common form is the infantile or nephropathic type form and is characterized by Fanconi syndrome with growth retardation, renal rickets, hypokalemia, polyuria, hypothyroidism and progressive renal failure. ${ }^{7}$ Generally renal fanconis syndrome becomes apparent 3-6 months after birth in nephropathic calcinosis and leads to end stage renal disease at age of 10 20 years. $^{8}$

Adolescent cystinosis was first described by goldmen et al characterized by the onset in the first or second decade of life with a mild nephropathy and the typical corneal and conjunctival cystine deposits but with the absence of retinopathy. ${ }^{9}$ Adult or benign type is characterized by characteristic corneal crystals and absent or minimal photophobia and absence of renal involvement.10

Ocular manifestations is characterized by deposition of crystals in cornea, iris, anterior lens surface and retina. ${ }^{11}$ Corneal crystals may be absent or minimal in first year of life ${ }^{12}$ with progressive crystal deposition leading to gradual loss of visual acuity. ${ }^{13}$ Photophobia and visual impairment increase with age and deposition of crystals.

Retinal involvement includes patchy depigmentation of the retinal pigment epithelium, mottled depigmentation of the macula that is more prominent and irregular toward the periphery. ${ }^{14}$

Other complications include corneal infiltration, filamentous and band keratopathy, impaired tritan colour vision.

Early diagnosis and treatment with renal transplantation and oral cysteamine can change the course of this disease. ${ }^{15}$ Renal transplantation has improved the prognosis for nephropathic cystinosis. After renal transplantation, fanconi syndrome does not develop in the recipients and cystinosis does not recur in the graft however, cystine deposition continues to accumulate in nonrenal tissue leading to multi-system dysfunction. ${ }^{13}$

Cysteamine ( $\beta$-mercaptoethyamine) specific agent that has a biochemical structure similar to cysteine and can deplete cystine from the patients' cells. Oral cysteamine, especially given before 2 
years of age, has been demonstrated to lower the intracellular cystine content by $95 \%$ and has proven efficacy in delaying renal glomerular deterioration, enhancing growth, preventing hypothyroidism and lowering muscle cystine content. ${ }^{16}$ The dosage for cysteamine treatment is 50 $90 \mathrm{mg}$ of free base/kg every 6 hours to maintain leukocyte cystine levels to less than $1 \mathrm{nmol}$ of half cystine per mg of protein when measured five hours after a dose.

The treatment for ocular complication include supportive treatments, topical cysteamine and corneal transplantation. Systemic cysteamine has demonstrated no effect on corneal accumulation and does not improve ocular symptoms. ${ }^{17}$

Topical cysteamine $0.5 \%$ given every 1 hour or at least 6 times a day has been shown to reduce corneal crystal deposition. After penetrating keratoplasty, grafts usually maintain clear with minimal crystals deposition. ${ }^{18}$

CONCLUSION: Cystinosis is a rare autosomal recessive disorder. The characteristic deposition of corneal crystals is one of the diagnostic criteria, which is very useful and could be discovered with general slit lamp examination. Early diagnosis and treatment with renal transplantation and oral cysteamine can lead to improvement in overall life expectancy. Topical cysteamine and corneal transplantation in advanced cases for ocular complications have shown promising results.

\section{REFERENCES:}

1. Abderhalden E. Familiare cystindiathese. Hoppe Seylers Zeitschr f physiol Chemie 1903; 38: 557-61.

2. Anikster Y, Shotelersuk V, Gahl WA. CTNS mutations in patients with cystinosis. Hum Mutat 1999; 14: 54-8.

3. Anikster Y, Lucero C, Touchman JW, Huizing M, McDowell G, Shotelersuk V, et al. Steady-state pharmacokinetics and pharmacodynamics of cysteamine bitartrate in paediatric nephropathic cystinosis patients. Br J Clin Pharmacol 2003; 56: 520-5.

4. Burki E. Ueber Die Cystinkrankheit im Kleinkindesalter unter besonderer Berucksichtigung des Augenbefundes. ophthalmologica 1941; 101: 257.

5. Bickel H. Cystine storage disease with aminoaciduria and dwarfism; Lignac-Fanconi disease. Acta Paediatr 1953; 42: 581-5.

6. Francois J. Hereditary chorioretinal degeneration and metabolic disturbances. Int Ophthalmol Clin 1968; 8: 911-27.

7. Francois J, Hanssens M, Coppieters R, Evens L. Cystinosis. A clinical and histopathologic study. Am J Ophthalmol 1972; 73: 643-50.

8. Geelen JM, Monnens LA, Levtchenko EN. Follow-up and treatment of adults with cystinosis in the Netherlands. Nephrol Dial Transplant 2002; 17: 1766-70.

9. Goldman H, Scriver CR, Aaron K, Delvin E, Canlas Z. Adolescent cystinosis: comparisons with infantile and adult forms. Pediatrics 1971; 47: 979-88.

10. Dodd MJ, Pusin SM, Green WR. Adult cystinosis. A case report. Arch Ophthalmol 1978; 96: 1054-7.

11. Kaiser-Kupfer MI, Caruso RC, Minkler DS, Gahl WA. Long-term ocular manifestations in nephropathic cystinosis. Arch Ophthalmol 1986; 104: 706-11. 
12. Gahl WA, Kuehl EM, Iwata F, Lindblad A, Kaiser- Kupfer MI. Corneal crystals in nephropathic cystinosis: natural history and treatment with cysteamine eye drops. Mol Genet Metab 2000; 71: 100-20.

13. Middleton R, Bradbury M, Webb N, O’Donoghue D, Van't Hoff W. Cystinosis. A clinicopathological conference. "From toddlers to twenties and beyond" Adult-Paediatric Nephrology Interface Meeting, Manchester 2001. Nephrol Dial Transplant 2003; 18: 2492-5.

14. Richler M, Milot J, Quigley M, O’Regan S. Ocular manifestations of nephropathic cystinosis. The French- Canadian experience in a genetically homogeneous population. Arch Ophthalmol 1991; 109: 359-62.

15. Markello TC, Bernardini IM, Gahl WA. Improved renal function in children with cystinosis treated with cysteamine. N Engl J Med 1993; 328: 1157-62.

16. Gahl WA. Early oral cysteamine therapy for nephropathic cystinosis. Eur J Pediatr 2003; 162 Suppl 1: S38-41.

17. Cantani A, Giardini O, Ciarnella Cantani A. Nephropathic cystinosis: ineffectiveness of cysteamine therapy for ocular changes. Am J Ophthalmol 1983; 95: 713-4.

18. Katz B, Melles RB, Schneider JA. Crystal deposition following keratoplasty in nephropathic cystinosis. Arch Ophthalmol 1989; 107: 1727-8.

\section{AUTHORS:}

1. Srinivas M. Ganagi

2. Shivaraj Budihal

\section{PARTICULARS OF CONTRIBUTORS:}

1. Associate Professor, Department of Ophthalmology, Srinivas Institute of Medical Sciences and Research Center, Mukka, Mangalore.

2. Assistant Professor, Department of Ophthalmology, Srinivas Institute of Medical Sciences and Research Center, Mukka, Mangalore.

\section{NAME ADDRESS EMAIL ID OF THE CORRESPONDING AUTHOR:}

Dr. Srinivas M. Ganagi, \#303 Staff Quarters, SIMS \& RC, Mukka, Mangalore-574146.

Email: srinivasganiga123@gmail.com

Date of Submission: 20/07/2014. Date of Peer Review: 21/07/2014. Date of Acceptance: 31/07/2014. Date of Publishing: 06/08/2014. 